\title{
Significado da supervisão acadêmica de estágio na formação profissional do assistente social
}

\author{
Meaning of the academic internship supervision in professional social worker training
}

\author{
Eliane Marques de Menezes Amicucci* \\ Cirlene Aparecida Hilário da Silva Oliveira**
}

\begin{abstract}
Resumo:
Neste artigo, a supervisão acadêmica de estágio em Serviço Social constitui objeto de reflexão. Essa modalidade de supervisão de estágio contribui no processo de formação profissional do estudante, no seu processo de ensino-aprendizagemofertando à análise crítica do trabalho profissional em sua totalidade, permitindo-o construir e reconstruir conhecimentos através do seu objeto de intervenção e dos fundamentos das dimensões teórico-metodológicas, ético-políticas e técnico-operativas da profissão. Trata-se de (re)pensar a supervisão acadêmica a partir de revisão de literatura sobre o tema, embasando teoricamente em legislações vigentes sobre estágio e supervisão em Serviço Social e orientações políticopedagógicas da Associação Brasileira de Ensino e Pesquisa em Serviço Social (ABEPSS) através da Política Nacional de Estágio(PNE) de 2010. Bem como, em autores que discutem sobre a temática supervisão de estágio,objetivando tratar a supervisão acadêmica de estágio para além de uma atividade sistemática, mas, principalmente do seu significado na formação profissional dos futuros assistentes sociais. A revisão de literatura permitiu identificar, principalmente que a supervisão acadêmica é a síntese da atividade de estágio e mediação para a formação do conjunto de competências e habilidades teórico-metodológicas, ético-políticas e técnico-operativas dos estudantes de Serviço Social.
\end{abstract}

Palavras-Chave: Estágio supervisionado. Formação profissional. Serviço Social. Supervisão acadêmica. Trabalho profissional.

\begin{abstract}
:
In this article, the academic internship supervision in Social work is the reflection object. This internship supervision mode helps in the process of student vocational training in the teaching-learning process your offering critical analysis of professional work in your entirety, allowing you to build and rebuild knowledge through your object of intervention and of the foundations of theoretical-methodological, ethical dimensions-and operating-technical policies of the profession. It's (re)thinking academic supervision from the review of literature on the subject, theoretically existing legislation in being on stage and supervision in Social work and pedagogic-political guidelines of the Brazilian Association of education and Research in Social Service (ABEPSS) through the National Policy stage (PNE) of 2010. As well, as authors who discuss about internship supervision, in order to handle the academic supervision of probation in addition to a systematic activity, but mainly of your meaning in professional training of future social workers. The literature review identified mainly academic supervision is the synthesis of the activity of training and mediation for the formation of the set of skills and theoretical-methodological skills, ethical policies and operating of technical students of Social Service.
\end{abstract}

Keywords: Supervised apprenticeship. Vocational training. Social Service. Academic supervision. Professional work.

\footnotetext{
* Doutora em Serviço Social da Faculdade de Ciências Humanas e Sociais- UNESP/Franca. Docente do curso de Serviço Social da FEF.

** Doutora em Serviço Social pela UNESP. Docente do curso de graduação e pós-graduação em Serviço Social da Faculdade de Ciências Humanas e Sociais -UNESP/Franca.
} 


\section{Introdução}

Neste artigo apresentou-se uma revisão de literatura acerca da supervisão acadêmica de estágio em Serviço Social, com embasamento teórico em legislações vigentes sobre estágio e supervisão em Serviço Social e orientações político-pedagógicas da Associação Brasileira de Ensino e Pesquisa em Serviço Social (ABEPSS) através da Política Nacional de Estágio (PNE) de 2010, bem como em autores que discutem sobre a temática supervisão de estágio, como: Lewgoy (2009); Barbosa (2004);Oliveira(2003); Albiero (2000). As reflexões presentes neste artigo teve por objetivo tratar a supervisão acadêmica de estágio para além de uma atividade sistemática, mas, principalmente do seu significado na formação profissional dos futuros assistentes sociais.

As competências e também habilidades profissionais são construídas processualmente a partir da atividade de estágio supervisionado e precisam ser refletidas, questionadas, problematizadas durante a supervisão acadêmica, por isso, ela se torna elemento síntese da atividade de estágio, envolvendo a análise da totalidade da profissão a partir do que se vivencia nos campos de estágio.

O estágio supervisionado é uma atividade curricular obrigatória, que a partir das Diretrizes Curriculares de 1996 do curso de Serviço Social propõem à capacitação teóricometodológica, ético-política e técnico-operativa, devendo ser dinamizada de acordo com a realidade social, a partir do contexto político-econômico-cultural das relações sociais.

O estágio, como espaço de aprendizagem profissional, significa o momento de apreensão da realidade profissional em seus aspectos difusos, tensos, contraditórios, os quais possam favorecer a relação na dimensão da prática profissional e na prática social dos sujeitos (OLIVEIRA, 2003, p. 50).

É nesse momento, através da inserção dos estudantes nos espaços sócioocupacionais que a atividade de estágio propicia o contato direto à população e a identificação das manifestações da questão social que permeiam as relações desses sujeitos, conhecendo a atuação cotidiana do assistente social e suas estratégias de intervenção, apreendendo os conhecimentos teórico-metodológicos, ético-políticos, técnico-operacionais que orientam o exercício profissional, permitindo-os experimentar o trabalho profissional,

O estágio é o momento da vida acadêmica do aluno em que se põe face a face com a prática profissional do Serviço Social. É ele que permite ao aluno aproximações sucessivas com a realidade institucional, com a realidade da demanda e com os desafios que se colocam ao trabalho do Assistente Social na sua relação com a sociedade. É ele também que confere ao ensino do Serviço Social uma dimensão teórico-prática (ALBIERO, 2000, p. 44). 
A atividade de estágio supervisionado em Serviço Social pressupõe o olhar crítico, investigativo e reflexivo do cotidiano profissional, capaz de propiciar o enfrentamento das situações que são colocadas à profissão e não somente no âmbito do aprendizado das competências e habilidades profissionais, isto é, na execução das atividades profissionais que restringe a formação ao treinamento e adestramento desse estudante às dinâmicas institucionais.

Dada a natureza investigativa e interventiva da profissão, o estágio propicia ao estudante desenvolver habilidades, responsabilidades, compromisso, permitindo a construção da identidade profissional, pois se identifica com suas especificidades e a totalidade que a envolve no âmbito da dinâmica das relações sociais e institucionais.

Esse processo de ensino-aprendizagem é viabilizado via supervisão direta de estágio que consiste num acompanhamento direto e sistemático do estudante, envolvendo o supervisor de campo e acadêmico, com base em planos de estágios, elaborados no conjunto: Unidade de Formação Acadêmica (UFA) e campo de estágio, tendo como referência a Lei 8662/93 e o Código de Ética do Profissional de 1993, Diretrizes Curriculares (1996), que preconiza a "indissociabilidade entre a supervisão acadêmica e de campo", a Resolução no 533/2008do Conselho Federal de Serviço Social (CFESS), Lei 11788/2008 e Política Nacional de Estágio da Associação Brasileira de Ensino e Pesquisa em Serviço Social (ABEPSS) de 2010.

Nesse processo pode-se garantir uma formação profissional com valores éticopolíticos, competências metodológicas e habilidades operativas em consonância com o projeto ético-político para o enfrentamento das situações futuras do trabalho profissional.

Essas competências não se constroem somente a partir de conhecimentos formais, mas especialmente a partir da vivência da construção de saberes pelo estudante viabilizada pela ênfase em processos pedagógicos que os instrumentalizem para o exercício profissional, enfrentando os desafios cada vez mais complexos que o mundo do trabalho profissional deles demanda, respectivamente, nos campos de estágio.

É nessa perspectiva que compreende-se a supervisão acadêmica, como lócus de instrumentalização para (re)pensar as ações desenvolvidas e vivenciadas nos campos de estágio. Enfatizando que essa instrumentalização não significa preparar o estagiário tecnicamente, mas sim, articulando às dimensões teórico-metodológica e ético-política, para que se indague o porquê, para quê, quando e como fazer determinadas ações/intervenções.

Parte-se da premissa que a supervisão acadêmica é a mediação na formação do conjunto de competências teórico-metodológicas, ético-políticas e técnico-operativas, que 
orientam o pensar e o agir profissional articulado à análise dos fundamentos do Serviço Social e dos processos de trabalho em que o profissional de Serviço Social se insere. É nessa dimensão que será discorrida e analisada a supervisão acadêmica de estágio em Serviço Social.

\section{O Significado da Supervisão Acadêmica de Estágio em Serviço Social na Formação Profissional}

O debate sobre a atividade de estágio supervisionado e com ela a supervisão vem ganhando relevância e visibilidade nas discussões do conjunto CFESS/CRESS e demais entidades da categoria profissional como a Executiva Nacional de Estudantes de Serviço Social (ENESSO) e ABEPSS, em especial a partir da construção da Política Nacional de Estágio (PNE) em 2010 pela ABEPSS que apresenta as orientações para operacionalização da atividade de estágio e as particularidades da supervisão acadêmica.

A supervisão acadêmica é um componente curricular que deve ocorrer em encontros semanais de, no mínimo 03 (três) horas, conforme PNE (ABEPSS, 2010, p. 29), sob a orientação de um professor, assistente social, denominado supervisor acadêmico, além disso, a supervisão acadêmica poderá ser realizada em pequenos grupos, conforme a PNE (ABEPSS, 2010, p. 17) para “[...] conhecer e refletir com os estagiários a realidade profissional nos campos de estágio, reconhecer os limites e possibilidades das respostas profissionais nas diferentes organizações no enfrentamento das expressões da questão social."

A supervisão acadêmica revela sua particularidade frente à supervisão de campo, o supervisor acadêmico, na sala de aula busca articular os fundamentos históricos, éticos, teóricos, metodológicos e políticos da ação profissional, uma vez que há de se considerar o movimento do cotidiano institucional, em que se encontra o assistente social no campo. Dada essa particularidade, compreende-se a supervisão acadêmica:

[...] como componente curricular, deve ser prevista na matriz curricular do curso, mas a operacionalização desta deve ser diferenciada das demais disciplinas do curso, sua dinâmica deve articular conteúdos teórico-metodológicos e permitir espaços para o relato das atividades desenvolvidas pelos alunos, refletindo com os mesmos o fundamento das suas ações como futuros assistentes sociais (TEIXEIRA, 2013, p. 6). 
A supervisão acadêmica deve ser estruturada numa perspectiva de trabalho participativo e socioeducativo entre supervisores de campo/acadêmicos e estudantes, constituindo um espaço de ensino-aprendizagem, de reflexão e enfrentamento das situações que permeiam o trabalho profissional, na construção de saberes, conhecimentos da profissão, visando à qualificação no processo de formação profissional do assistente social, bem como a efetivação do projeto ético-político do Serviço Social.

Pensar a sistematização, todo o processo da supervisão de estágio implica ultrapassar sua metodologia e/ou técnica, vai além da inserção na matriz curricular do curso.

O que se quer dizer, é que se deve compreender a concepção de supervisão acadêmica, considerada como um desafio "[...] a dimensão teórico-metodológica e pedagógica que orienta o diálogo entre os sujeitos envolvidos diretamente no processo de supervisão de estágio [...]" (LEWGOY, 2009, p. 104) com a finalidade de uma formação profissional crítica. Logo, a ideia nesse artigo é que se reflita sobre o significado dessa supervisão:

\begin{abstract}
Desse modo, a supervisão acadêmica está imbricada diretamente com a finalidade social da profissão, que consiste entre outras questões em conhecer e refletir com os(as) estagiários(as), em pequenos grupos, a realidade profissional nos campos de estágio, reconhecer os limites e possibilidades das respostas profissionais nas diferentes organizações no enfrentamento das expressões da questão social, reconhecer e debater os elementos constitutivos do projeto profissional em curso nos espaços sociocupacionais e sua relação com o projeto hegemônico de profissão[...](ABEPSS, 2010, p. 17)
\end{abstract}

A supervisão acadêmica propicia a reflexão ao estudante sobre a contribuição da atividade de estágio supervisionado na sua formação profissional, além do trabalho profissional.

Nas particularidades da supervisão acadêmica encontramos a esfera reflexiva da dimensão educativa do trabalho profissional, esta "envolve a analise da conjuntura, a reflexão sobre os problemas do dia a dia, tendo como conteúdo as contradições econômicoideológicas da organização social capitalista, sob à luz do saber popular" (ELIAS; OLIVEIRA, 2008, p. 18). Essas situações devem ser (re)pensadas cotidianamente no âmbito da supervisão acadêmica, haja vista que o trabalho profissional deve ser realizado na perspectiva da práxis.

A práxis é utilizada para compreender, interpretar o mundo, por isso não pode ser utilizada no sentido utilitário, mas, sim, numa concepção filosófica, onde há para a 
realização de uma atividade consciente objetiva, possibilitando transformar a realidade social e não apenas interpretá-la (SÁNCHEZ VÁZQUEZ, 2007).

A práxis permite à transição da teoria á prática tornando-as indissociáveis, ela é elemento para possibilidade de atividades que visam à transformação social.

Sánchez Vázquez (2007, p. 231) apresenta algumas formas de práxis, dentre elas destacamos a práxis política, os atos dos sujeitos estão "orientados para sua transformação enquanto ser social e por isso, destinados a mudar suas relações econômicas, políticas e sociais [...]."

Essa práxis denominada também como práxis social está voltada aos grupos ou classes sociais que buscam a transformação de uma dada sociedade, que consiste essa atividade em uma atividade política.

Envolve certamente correlações de forças porque lida diretamente com o poder, inclusive com o próprio Estado, pois pode divergir das ideias, programas, projetos criados por este. Esta práxis social exige organização política, no caso aqui, mobilização e organização do proletariado, no sentido da luta para o enfrentamento das contradições entre as classes sociais.

Sánchez Vázquez (2007) afirma ainda, que a práxis política pressupõe as possibilidades inscritas na realidade social para que a mudança ocorra, portanto, ela deve ser consciente, organizada, dirigida para um fim. O proletariado precisa adquirir a consciência de classe para travar essa luta, a partir de estratégias e táticas visando à transformação social.

A práxis política vai ao encontro dos princípios do projeto ético-político profissional do assistente social, por isso, sua compreensão, apreensão e desenvolvimento no cotidiano profissional são essenciais para propiciar a consciência política da população atendida e sua própria consciência enquanto classe trabalhadora.

A atividade humana para se constituir enquanto práxis, precisa ser guiada por uma intencionalidade e por um fim, produzir algo, resultado e efetividade, tem que causar mudança, trata-se de uma atividade consciente.

Isso só é possível se o supervisor acadêmico reflete junto com o estudante essas situações, respeitando seus saberes construídos socialmente, entretanto, superando o aparente, analisando criticamente a realidade por todos vivenciada nos campos de estágio: supervisor de campo, estagiário, usuários do Serviço Social, reconhecer uma competência ou 
habilidade estimula e motiva o estagiário a continuar aprendendo, a pensar a sua prática para transformá-la.

O supervisor acadêmico é responsável pela articulação dos conhecimentos teóricos à prática profissional vivenciada no estágio, sendo realizada por um professor assistente social do curso (ABEPSS, 2010).

O papel do supervisor acadêmico é ser o facilitador no processo de ensinoaprendizagem no que tangeà apreensão dos conteúdos teóricos do curso com a realidade vivenciada pelos estudantes nos campos de estágio.

Perpassa pela apropriação da relação unidade teoria-prática do trabalho profissional, o supervisor acadêmico deve propiciar a (re)construção do objeto de intervenção profissional e o estudante precisa construir e (re)construir o conhecimento a partir da totalidade que envolve o trabalho profissional, "assim a particularidade pedagógica do processo de supervisão envolve o esforço de realizar o movimento da relação entre teoria e realidade[...]" (LEWGOY, 2009, p. 106).

Entretanto, essa afirmação tem se tornado um desafio na formação profissional e precisamente no processo de supervisão de estágio quando os estudantes dizem que na realidade teoria e prática não caminham juntas, reproduzem o usual jargão " na prática a teoria é outra".

Nos dizeres de Forti e Guerra (2010, p. 5), "é preciso romper com as práticas sociais e profissionais conservadoras que buscam a reprodução do existente", problematizar o senso comum que faz parte de ações/intervenções profissionais ainda conservadoras e que "impedem" de vislumbrar que a teoria dirige o pensamento à mudança do real e a prática supera o existente, desta forma: "a teoria e a prática constituem aspectos inseparáveis do conhecimento e devem ser consideradas na sua unidade." (KAMEYAMA, 1995, p.101apud BATTINI, 2009, p. 56).

O debate em torno da unidade entre teoria e prática perpassa à adoção de um referencial teórico-crítico (marxista) e um método de análise sobre a realidade, o método dialético, que permita ir além do aparente, da imediaticidade das respostas profissionais cotidianas, bem como compreender que está na base dos fundamentos históricos, teóricos, metodológicos do Serviço Social os percalços de intervenções e posturas conservadoras, que the servem de explicação e orientação teórico-prática e ainda as bases históricas que fundam a sociedade burguesa e da dinâmica que esta influencia diretamente a origem, significado da profissão e como ela é hoje. 
No processo de formação profissional esse debate é um entrave, por isso, considera-se que no processo de supervisão acadêmica, por ser o espaço de ensinoaprendizagem do trabalho profissional a partir da atividade de estágio supervisionado, é discutir justamente conteúdos atrelados à unidade teoria-prática com o que se vivencia nos campos de estágio, permitindo supervisor e estudante pensarem a conjuntura, realidade institucional e profissional, vivenciando uma práxis na qual ambos refletem sobre a ação desenvolvida, no contexto amplo das relações sociais.

Nesta perspectiva, a supervisão acadêmica de estágio é essencial à formação do estudante de Serviço Social, que resgata e possibilita a passagem de uma "[...] consciência teórica para uma consciência crítica." (ANDRAUS et al., 1996 apud LEWGOY; SCAVONI, 2002, p. 1).

Diante das necessidades postas hoje à profissão é preciso estar atento ao reordenamento do padrão de acumulação capitalista, bem como de regulação da vida social, exigindo do profissional o redimensionamento na sua forma de pensar e agir, elementos estes que devem ser problematizados no processo de supervisão acadêmica.

Neste processo de supervisão encontra-se o objetivo de acompanhar o estudante no desenvolvimento e análise crítica da relação teoria-prática no desenvolvimento de suas atividades nos campos de estágio, daí compreende-se que é a partir da supervisão acadêmica que se tem, primordialmente, as condições para a orientação de que teoria e a prática não podem ser dissociadas.

Por isso, o supervisor acadêmico possui uma atribuição importante no processo de ensino-aprendizagem, este precisa estar instrumentalizado pedagogicamente, eticamente, e possuir a visão de totalidade da profissão para que instigue o estudante e/ouo direcione para a leitura crítica da realidade que se desenvolve o trabalho profissional, seu processo histórico, mas, principalmente hoje que este se realiza num contexto tão adverso e desfavorável à classe trabalhadora.

Para este supervisor acadêmico precisa estar claro que o Serviço Social, historicamente, atua nas múltiplas refrações da questão social, conformadas na ordem social contemporânea e seus procedimentos técnicos são instrumentais vinculados a uma intencionalidade, que extrapola a requisição institucional, cuja demanda nos é colocada sem lapidação teórica e ético-política. Só a competência do profissional, pelo conhecimento teórico-metodológico é capaz de decifrar seu significado. 
Ao longo do desenvolvimento de sua história e legitimação, os assistentes sociais têm enfrentado diferentes dilemas na profissão. Alguns, aos quais se podem chamar de "falsos dilemas", estão atrelados às características próprias da profissão e decorrem de sua situação na divisão sociotécnica do trabalho na sociedade contemporânea. São essas atividades, as de caráter burocrático, assistencial, pragmático, que conformam àprofissão como uma prática eminentemente interventiva.

A ênfase nessas atividades tem traduzido em respostas profissionais fragmentadas, trabalhadas nos limites instituídos socialmente. Nessa perspectiva, o assistente social dificilmente tem uma visão totalizadora da problemática que enfrenta, não acionando, portanto, o seu potencial para modificar o seu modo de intervir e daí se discursa que teoria e prática não se relacionam.

Outros dilemas têm por base a perspectiva de que a teoria dá conta de explicar a realidade, mas não instrumentaliza a prática cotidiana do assistente social. Nessa ótica, é facilmente embutida a contradição de um discurso crítico e uma prática baseada no senso comum e ainda, a efetivação da relação dicotômica entre profissionais que "pensam" e profissionais que "fazem".

A superação desta tensão vai demandar dos assistentes sociais uma disponibilidade a não mais pensarem no trabalho profissional em si, independentemente, de seus fundamentos e de suas determinações, assimilando ao nível da racionalidade, à necessária unidade entre a teoria e a prática como determinantes complementares que incidem na ação particular dos profissionais, o que Ihes vai possibilitar a garantia do movimento dialético pensamento/ação.

O desafio está em apreender e desvelar os limites e as possibilidades potenciais presentes na dinâmica da vida cotidiana profissional, dessa maneira, para desencadear um processo de desvelamento do que se oculta nas práticas cotidianas dos assistentes sociais e, concomitantemente, apreender às possibilidades do "novo", faz-se necessário a incorporação de um método de análise dos processos sociais, do objeto de intervenção profissional, o método dialético, que possibilita o resgate e a reconstrução da ação cotidiana dos assistentes sociais, capturando suas determinações e seus nexos através de estudo reiterado e crítico da realidade social, além disso, permite ao profissional, segundo Netto (2011) extrair de seu objeto as suas múltiplas determinações.

O trabalho profissional do assistente social acontece num contexto social complexo que abarca dificuldades, limites e o fato de que certas situações, circunstâncias, realidades 
não são confortáveis, conformáveis, domáveis, como geralmente gostaríamos que fossem, o que implica em enfrentar desafios que não são simples,cuja ação vai requerer escolhas, diferentes conhecimentos.

Este trabalho profissional está imerso na complexidade da realidade, que é mutável e se caracteriza por um conjunto de ações. Segundo Forti e Guerra (2010) é necessário que se tenha uma visão dos processos sociais como totalidades que secompõem de vários aspectos e âmbitos e que possuem níveis diferentes de complexidade.

Uma leitura do real com essa amplitude necessita de teorias macroscópicas sobre a sociedade, as quais permitam que se apreenda tanto os elementos estruturais quanto aos conjunturais e as relações entre os vários elementos que compõem a realidade na qual estamos inseridos. Mais ainda, faz-se necessária uma teoria que permita perceber como os principais dilemas contemporâneos se traduzem nas particularidades do Serviço Social e se expressam nas requisições e competências socioprofissionais e na cultura profissional (FORTI; GUERRA, 2010).

É nessa realidade complexa que o assistente Social vai desenvolver suas investigações e posteriores intervenções. Consideramos a intervenção profissional à expressão da prática social do assistente social que se materializa nos modos de realizar uma interposição consciente na realidade social; expõe as formas de conhecer, interferir, pensar, agir.

Intervenção, nesse sentido significa ser ou estar presente; implica um movimento de ações concretas, orientadas para alguma transformação social. Como dimensão privilegiada da prática profissional, objetiva-se em uma proposta de ação que articula pensamento e discurso. $O$ constructo "pensamento e ação" não é unidade, mas relação.

Pensar acerca da realidade permite compreender que o exercício profissional do assistente social não se realiza isolado do real, que está imbricado na sua complexidade e contraditoriedade, pois está inserido numa sociedade capitalista, bem como o homem é sujeito histórico do real, e assim sendo, o profissional necessita, “[...] além de conhecer a realidade na sua complexidade, criar meios para transformá-la na direção de determinado projeto socioprofissional" (PONTES, 2000, p. 43).

O grande desafio posto ao profissional de Serviço Social é desenvolver a capacidade de decifrar a realidade e construir propostas criativas e efetivar direitos, se apropriando de aportes teórico-metodológicos, ético-políticos, técnico-operativos que norteiam seu trabalho. 
Compreende-se assim, que a supervisão acadêmica constitui-se elemento síntese na atividade de estágio supervisionado, porque precisa ser analisado e refletido sobre o trabalho profissional que incide na realidade dos espaços sócio-ocupacionais.

É preciso lembrar que nas Diretrizes Curriculares da ABEPSS de 1996 a atividade de estágio, insere-se no núcleo de fundamentos do trabalho profissional, no qual o trabalho é tratado como categoria dialética, como práxis, e, essa concepção deve perpassar toda a formação profissional estendendo-se à atividade de estágio.

O núcleo de fundamentos do trabalho profissional, articulado aos demais núcleos, envolve a compreensão do Serviço Social como uma especialização do trabalho, e, as dimensões histórica, teórica, metodológica, e técnica da profissão são necessárias para apreender a formação, os componentes do trabalho profissional e, em particular, as formas de pensar dos assistentes sociais, que implicam nos modos de agir.

\begin{abstract}
Desse modo, os caminhos do estágio supervisionado se encontram com os da construção de uma formação profissional que sedimente o significado social da profissão. Para tanto, terá de responder, entre outros desafios, às contradições presentes na política educacional, na ideologia capitalista impressa nas universidades brasileiras, na efetivação das Diretrizes Curriculares pelas Unidades de Formação Acadêmica - UFAS, nos espaços institucionais em que se efetiva o trabalho dos assistentes sociais e dos estagiários, nas transformações e exigências do mercado de trabalho [...] (LEWGOY, 2009, p. 45).
\end{abstract}

Esses aspectos trazidos pela autora estabelecem os desafios postos ao estágio supervisionado para o direcionamento de uma formação profissional crítica e competente para que futuros profissionais compreendam o significado social da profissão e que articule as dimensões ético-políticas, técnico-operativas e teórico-metodológicas para o enfrentamento das condições objetivas do trabalho cotidiano profissional e da vida da população demandatária de seus serviços.

Isso só é possível se no processo de supervisão de estágio, especificamente a supervisão acadêmica, o supervisor co-relacionar a vivência dos estudantes nos campos de estágio com as disciplinas, conteúdosprivilegiando a análise conjuntural de processos sociais em curso na sociedade geradora das múltiplas expressões da questão social para possibilitar a elaboração e reelaboração do objeto de intervenção e a criação de estratégias comprometidas com a dimensão ético-política do projeto profissional em suas particularidades sócio-ocupacionais.

Considerando que a atividade de estágio supervisionado se insere no núcleo do trabalho profissional, e que a supervisão acadêmica está sendo compreendida como a 
mediação das dimensões do trabalho profissional. Faz se necessário analisar, mesmo que brevemente, o que se entende por tais dimensões, já que estas devem ser trabalhadas de forma articulada no processo de supervisão acadêmica para que o estagiário apreenda todo o complexo da totalidade do trabalho profissional e supere a relação de que se tem, que no estágio se aprende o "fazer profissional", restringindo ao aprendizado somente a dimensão técnica do Serviço Social.

\section{A Supervisão Acadêmica como Mediação das Dimensões Teórico-Metodológicas, Ético-Políticas e Técnico-Operativas do Serviço Social}

O exercício profissional constitui-se de uma totalidade formada pelas dimensões teórico-metodológica, ético-política e técnico-operativa; e estas se dão de forma articulada, embora possuam suas particularidades.

Pensar o exercício profissional a partir destas dimensões leva à compreensão do significado social da ação profissional, através da teoria e realidade, teoria e prática para que a intervenção profissional se constitua como finalidade objetiva.

Para isso, deve-se ultrapassar e/ou considerar que a intervenção vai além de manuseios de instrumentos e técnicas,precisa ser considerado a qualificação dessa intervenção e ter direcionamento do projeto ético-político-profissional.

A dimensão teórico-metodológica da profissão refere-se ao processo de investigação e análiseda realidade social e suas demandas à luz de uma teoria social; a dimensão ético-política permite avaliar as prioridades, alternativas da ação profissional, guia-se pelos valores e finalidades e avalia as consequências dessa ação,além das condições objetivas e subjetivas do trabalho profissional.

Ressalva-se que a dimensão técnico-operativa precisa ser dotada de intencionalidades e que perpassadas pela dimensão ético-política e que encontra-se respaldada na dimensão teórico-metodológica a qual norteia a compreensão dos limites e possibilidades da intervenção profissional, pois é no movimento contraditório da realidade social que o exercício profissional faz parte.

Reduzir a dimensão técnico-operativa do Serviço Social ao manuseio de instrumentos e técnicas conduz somente ao alcance dos interesses institucionais e as determinações capitalistas. 
Para que a intervenção profissional ocorra e o assistente social consiga responder às demandas institucionais e sociais, já que está inserido na divisão social e técnica do trabalho e faz parte da especialização do trabalho coletivo, ele necessita, segundo Guerra(2013) de fundamentos teóricos-metodológicos, conhecimentos e saberes interventivos, habilidades técnico-profissionais, procedimentos teóricos-metodológicos, uma perspectiva ética. Assim, a sua intervenção é atribuída um caráter político.

Quando a ação profissional é realizada de forma imediata, a dimensão técnicooperativa é mobilizada porque responde instrumentalmente às demandas apresentadas, o que pode obscurecer à legitimidade da profissão (GUERRA, 2013).

Segundo Guerra(2013) a dimensão técnico-operativa possibilita ao assistente social legitimar o ethos profissional, bem como uma cultura que envolve objeto, objetivos, valores, racionalidade, técnicas, instrumentos, conhecimentos, teorias.

Esta dimensão também é constituída por elementos como estratégias, táticas, conhecimento da realidade e dos procedimentos para operacionalização dos recursos técnico-organizacionais, como os instrumentos.

Os instrumentos e técnicas efetivam as finalidades profissionais como direção social de suas ações, que quando usadas com criticidade e de forma competente oferecem respostas, mas precisam estar articulados às demais dimensões da profissão.

Por isso, a necessidade no exercício profissional de articular a dimensão técnicooperativa com os questionamentos: sobre o quê, como fazer, por que, para quê e quando fazer.

Evidencia-se também, que as demandas que chegam até o Serviço Social são de forma imediatas, sendo necessário o profissional ultrapassar essa visão imediatista, caso contrário operacionalizará os instrumentos de forma conservadora.

Guerra (2013) afirma que no cotidiano infere-se respostas imediatistas, ações pragmáticas que atendem às necessidades de mera reprodução individual, o que pode levar a adesão ao jargão que na "prática a teoria é outra, pois o cotidiano não permite a reflexãodessa prática e essa não reflexão estabelece uma "[...] distância entre a elaboração teórica e a intervenção profissional" (GUERRA, 2013, p. 54). É importante mencionar que toda ação é guiada teleologicamente por uma teoria, seja ela conservadora ou crítica.

No cotidiano profissional também se operacionaliza as políticas sociais que podem potencializar ou limitar sua ação profissional, dada as suas características de ser 
fragmentadas, seletivas, moldando a intervenção profissional com ações pontuais, pragmáticas, instrumentais.

Nesse âmbito, a dimensão técnico-operativa fica relegada apenas ao cumprimento de normas, regulamentos, ou seja, para atender aos objetivos institucionais. Ao mesmo tempo que o cotidiano condiciona à ação profissional, pode-se superá-lo através da análise e reflexão da situação concreta dessas demandas.

Atrelada a essa afirmação, a dimensão teórico-metodológica capacita e guia aos profissionais para interpretação desse cotidiano à luz de uma teoria social, aqui reporta-se à teoria social crítica, uma vez que ela permite visualizar esse cotidiano alienado, instrumental, direcionando aos profissionais para a sua superação, bem como na construção de estratégias profissionais frente às demandas sociais e institucionais.

Na outra posição, há a dimensão ético-política que embora perpasse a subjetividade do profissional, vai permitir trabalhar na direção dos interesses das demandas sociais, na luta pela garantia dos direitos da população, bem como na orientação, no diálogo, na construção conjunta entre profissional e população de possibilidades para resultados positivos nas intervenções, além disso, existem os princípios éticos que proporcionam a lembrança de qual direção precisa ser seguida nesse cotidiano profissional.

Com essas reflexões pode-se afirmar que o supervisor acadêmico precisa estabelecer a relação entre essas dimensões a partir dos conteúdos trabalhados na supervisão acadêmica, embora o trabalho profissional aconteça numa dada realidade que é dinâmica e mutável.

Entretanto, se num certo momento se discute com o estagiário uma determinada intervenção profissional, é preciso que se reflita que esta foi guiada por uma fundamentação teórica, um modo de ler e interpretar o real, além das demandas sociais e institucionais (dimensão teórico-metodológica); que para essa intervenção foram utilizados instrumentos e técnicas, seja uma entrevista, visita domiciliar, orientações, a escuta, encaminhamentos, estratégias, táticas porque houve um objetivo a ser alcançado (dimensão técnico-operativa) e que essa intervenção teleologicamente realizada tinha um público-alvo, uma direção social, uma demanda específica, ou seja, a luta pela garantia de direitos de uma população que chega até o Serviço Social e que são esclarecidas, orientadas, estabelece um diálogo na perspectiva da emancipação humana e social (dimensão ético-política). Reitera-se, portanto, que não se pode trabalhar tais dimensões de forma dissociadas e no processo de supervisão acadêmica isso precisa ficar evidente. 
Através da análise do trabalho profissional na sua totalidade, o supervisor acadêmico quando percebe que o estagiário encontra dificuldade de fazê-lo, pode conduzílo ao exercício da passagem do abstrato ao concreto pensado na realidade do trabalho profissional, bem como se a intervenção profissional não ultrapassou o campo da imediaticidade, também precisa ser refletido e estudar novas possibilidades, que a partir da tríade singularidade-universalidade-particularidade, permite-se a reconstrução do objeto de intervenção profissional, assim, a reconstrução das experiências profissionais já acumuladas. A categoria mediação serve para instrumentalizar o supervisor acadêmico e estagiários para (re)pensarem o trabalho profissional.

Considerar a realidade enquanto totalidade, implica compreendê-la como um complexo formado pelos níveis do singular, do particular e do universal, níveis nos quais o real se movimenta: o que é singular pode se tornar particular, este pode se tornar universal e assim sucessivamente. É exatamente esse movimento dialético da realidade social entre os níveis que se denomina totalidade.

Presencia-se neste ínterim, a supervisão acadêmica de estágio em Serviço Social, como ato educativo que propicia a problematização, reflexão do trabalho profissional, fazendo o caminho do singular ao universal, dando ênfase à intervenção que particulariza o Serviço Social no âmbito das relações sociais.

É preciso esclarecer que a atribuição do supervisor acadêmico não é em hipótese alguma avaliar o trabalho realizado pelo assistente social supervisor de campo, na perspectiva do certo ou errado, mas enquanto processo de ensino-aprendizagem é direcionar o estagiário para a análise da totalidade do trabalho profissional (demandas, recursos institucionais disponíveis ou não, políticas sociais, trabalho em rede, etc), alicerçada nos conhecimentos teórico-metodológicos do Serviço Social conectada ao projeto éticopolítico que é intrínseco àformação profissional.

\footnotetext{
O estágio devidamente supervisionado, como componente curricular favorecendo àunidade teoria-prática, mais do que aprendizagem, compreende uma vivência, não podendo ser reduzido a um treinamento para aprender o 'como fazer' sem que o entendimento acompanhe o porquê e o para quê da ação. Daí entendermos que, no estágio, o aluno vivencia a práxis profissional e ao vivenciá-la aprende a utilizar o instrumental e a interagir numa rede institucional e pessoal, em situações concretas e desafiadoras (BARBOSA, 2004, p. 3).
}

Pensando na sistematização da supervisão acadêmica, esta precisa ser planejada de modo que atenda aos interesses e necessidades dos estagiários, para além da sala de aula, 
quando realizada em pequenos grupos, podem ser elencados conteúdos inerentes ao que se vivencia nos campos de estágio, que seja de uma área específica de atuação profissional e/ou que envolve a profissão de Serviço Social, principalmente o que envolve a ética profissional, atribuições e competências profissionais, como também a legalidade profissional, estes são exemplos de subsídios teóricos que podem fazer parte dos encontros da supervisão acadêmica.

Uma das atribuições do supervisor acadêmico também consiste no acompanhamento e orientação da construção do plano de estágio do estagiário, instrumento este imprescindível para se planejar as atividades de estágio a partir das orientações também do supervisor de campo. Este instrumento permite que ele identifique o significado do Serviço Social na instituição campo de estágio, bem como os recursos, programas, projetos, objetivos institucionais, objetivos profissionais, público-alvo, objeto de intervenção profissional, instrumentos e técnicas utilizados, políticas sociais existentes, bem como o significado do estágio supervisionado na formação profissional e da supervisão(acadêmica e de campo).

É no plano de estágio também que o estagiário apresenta suas atribuições e os objetivos que pretende alcançar. Durante sua execução (isso exige acompanhamento) e ao término do estágio, este instrumento precisa ser debatido entre supervisor de campo, acadêmico e estagiário para fins de avaliação do processo de ensino-aprendizagem acerca da atividade de estágio e principalmente se os objetivos elencados pelo estagiário foram alcançados ou não.

Outro instrumento que pode ser citado como aporte para o estagiário para a sistematização da atividade de estágio é o relatório, instrumento esse que é elaborado ao término do estágio e consiste em apresentar as atividades realizadas e toda vivência do estagiário no campo de estágio, também sua construção é guiada pelo supervisor acadêmico, outra atribuição deste.

A orientação do supervisor acadêmico para sua construção perpassa pela ética profissional, porque este relatório consiste num documento, e algumas informações do campo de estágio, principalmente da população atendida precisam ficar sobre sigilo, salvaguardando sua identidade, por isso, o relato precisa circunscrever o processo de aprendizagem do trabalho profissional, analisando criticamente os desafios e possibilidades do assistente social para o enfrentamento das manifestações da questão social em seu cotidiano. 
O diário de campo necessita ser incentivado para que os estagiários o utilize tanto para o registro das atividades diárias, como instrumento para propiciar a reflexão sobre o trabalho profissional e as atividades desenvolvidas, bem como suas facilidades, dificuldades, desafios encontrados no campo de estágio, este também o subsidia para a construção do relatório.

O supervisor acadêmico dessa maneira, instiga o estagiário a utilizar o arcabouço teórico-metodológico, técnico-operativo e ético-político apreendido em sala de aula para desvendar a realidade, para compreender as manifestações da questão social e também para ser propositivo no sentido de refletir sobre as possibilidades de intervenções frente à situação vivenciada. Além do relato da sua atividade de estágio, ele é capaz de exercitar sobre a relação teoria e prática e a pensar sobre estratégias de intervenção.

Nesse âmbito, defende-se a ideia de que a supervisão acadêmica é a mediação das dimensões teórico-metodológicas, ético-políticas e técnico-operativas do Serviço Social, bem como é a síntese da atividade de estágio supervisionado contribuindo para a construção de um conjunto de competências e habilidades para o futuro exercício profissional dos estudantes, condizentes ao perfil preconizado pelas Diretrizes Curriculares da Associação Brasileira de Ensino e Pesquisa em Serviço Social de 1996.

\section{Considerações Finais}

O processo de acompanhamento sistemático de estudantes de Serviço Social via supervisão acadêmica é uma exigência presente nas Diretrizes Curriculares da ABEPSS de 1996, entretanto, ela tem ganhado destaque na Política Nacional de Estágio de 2010 também construída por essa entidade representativa trazendo elementos para sua operacionalização.

Compreende-se que a supervisão acadêmica necessita constantemente ser problematizada e desvelada, discutida para além de sua sistematização, precisa esclarecer qual o lugar ela ocupa e o seu significado na formação profissional estagiários de Serviço Social, bem como as atribuições do supervisor acadêmico.

As reflexões trazidas nestas páginas permitem afirmar que a tarefa principal dos supervisores acadêmicos é garantir a unidade didática entre ensino e aprendizagem, bem como a unidade teoria e realidade, desencadeando um processo reflexivo da totalidade da profissão junto aos estagiários. 
Neste processo de supervisão encontra-se o objetivo de acompanhar o estudante no desenvolvimento e análise crítica da relação teoria-prática no desenvolvimento de suas atividades nos campos de estágio.

O supervisor acadêmico assume uma ação educativa ao intercambiar seus saberes e competências na relação com o outro. No entanto, para que os supervisores acadêmicos possam materializar essa proposta é necessário que estejam instrumentalizados teoricamente, técnica e politicamente para que sejam capazes de desvendar as contradições presentes no real. A supervisão de estágio, nesse sentido, pode contribuir para a problematização da intervenção profissional (suas ações e propostas).

É um processo educativo que requer conhecimentos especializados e constante preparo profissional para que seja possível desenvolver uma postura investigativa e reflexiva do estudante.

A supervisão acadêmica como um processo didático-pedagógico, evidencia o ensino teórico-prático articulado aos objetivos e conteúdo programático do curso de Serviço Social.

No processo de supervisão acadêmica, leva-se a um repensar da postura profissional, refletindo constantemente sua prática que necessita estar vinculada a um projeto profissional crítico, propiciando ao estagiário os ditames do fazer e saber profissional num processo dinâmico e criativo, tendo em vista possibilitar a elaboração de novos conhecimentos.

Sob essa ótica, a supervisão acadêmica de estágio deve ser efetiva e globalmente integrada ao conteúdo do curso, envolvendo o processo de ensino-aprendizagem pressupondo a integração dos componentes que subsidiam a formação profissional em todos os espaços que esse processo se concretiza (tanto nas Unidades de Formação Acadêmica, quanto nas unidades campos de estágio).

É pertinente, então, que essa concepção seja condizente com o projeto de formação profissional em Serviço Social que busca contemplar uma base teórica e metodológica, ético-política e técnico-operativa, reflexiva do fazer profissional, com base no projeto ético-político do Serviço Social tendo a supervisão acadêmica como mediação desse processo. 


\section{Referências}

ABEPSS - ASSOCIAÇÃO BRASILEIRA DE ENSINO E PESQUISA EM SERVIÇO SOCIAL. Política Nacional de Estágio (PNE). Brasília-DF: ABEPSS, 2010.

ABEPSS - ASSOCIAÇÃO BRASILEIRA DE ENSINO E PESQUISA EM SERVIÇO SOCIAL. Proposta básica para o projeto de formação profissional. Revista Serviço Social \& Sociedade, São Paulo, v. 17, n. 50, p. 143-171, abr. 1996.

ALBIERO, C. M. G. Ensinar e aprender: desafios constantes na formação profissional em Serviço Social. 2000. 227 f. Dissertação (Mestrado em Serviço Social) - Pontifícia Universidade Católica de São Paulo, São Paulo, 2000.

BARBOSA, A. M. G. O importante papel do estágio no desenvolvimento de competências. Revista Ágora, Rio de Janeiro, v. 1, n. 1, p. 89-95, out. 2004. Disponível em: <http://www.assistentesocial.com.br/biblioteca.php\#agora $>$. Acesso em: 3 mar. 2008.

BATTINI, O. Atitude investigativa e prática profissional. In: BAPTISTA, M. V.; BATTINI, O. A prática profissional do assistente social: teoria, ação, construção de conhecimento. São Paulo: Veras Editora, 2009.

ELIAS, W.; OLIVEIRA, C. A. H. S. As diferentes configurações da dimensão socioeducativa do Serviço Social brasileiro na sua trajetória histórica profissional. Revista Serviço Social \& Realidade, Franca, v. 17, n. 2, p. 61-83, 2008.

FORTI, V.; GUERRA, Y. Serviço social: temas, textos e contextos: coletânea nova do Serviço Social. In: FORTI, V., GUERRA, Y. (Org.). Na prática a teoria é outra? Rio de Janeiro: Lumen Juris, 2010. p. 3-23.

GUERRA, Y. Formação profissional em Serviço Social: polêmicas e desafios. In: SILVA, J. F. S. da; SANT'ANNA, R. S.; LOURENÇO, E. A. de S.(Org.). Sociabilidade burguesa e Serviço Social. Rio de Janeiro: Lumen Juris, 2013.

LEWGOY, A. M. B. Supervisão de estágio em Serviço Social: desafios para a formação e o exercício profissional. São Paulo: Cortez, 2009.

LEWGOY, A. M. B.; SCAVONI, M. L. A. Supervisão em Serviço Social: a formação do olhar ampliado. Textos \& Contextos, Porto Alegre, n. 1, p. 1-9, nov. 2002. Disponível em: $<$ http://www.revistaeletronicas.pucrs.br>. Acesso em: 4 maio 2008.

NETTO, J. P. Introdução ao estudo do método de Marx. São Paulo: Expressão Popular, 2011.

OLIVEIRA, C. A. H. S. A centralidade do estágio supervisionado na formação profissional em Serviço Social. 2003. 178 f. Tese (Doutorado em Serviço Social) - Faculdade de História, Direito e Serviço Social, Universidade Estadual Paulista Júlio de Mesquita Filho, Franca, 2003.

PONTES, R. N. Mediação: categoria fundamental para o trabalho do assistente social. In: CFESS/ABEPSS; CEAD/UNB (Org.) $O$ trabalho do assistente social e as políticas sociais: capacitação em serviço social e política social. Brasília: CEAD/UNB, 2000. p. 51-63. 
SÁNCHEZ VÁZQUEZ, Adolfo. Filosofia da práxis. Buenos Aires: Clacso; São Paulo: Expressão Popular, 2007.

TEIXEIRA, R. J. A supervisão direta de estágio em Serviço Social: os desafios da supervisão acadêmica. In: CONGRESSO BRASILEIRO DE ASSISTENTES SOCIAIS, 14., 2013, Águas de Lindóia. Anais... Águas de Lindóia, 2013. 